\title{
Life-cycle energy analysis of buildings: a case study
}

\author{
Roger Fay, Graham Treloar and Usha Iyer-Raniga \\ School of Architecture and Building, Deakin University, Geelong 3217, Australia \\ E-mail: roger@deakin.edu.au
}

Energy use is a widely used measure of the environmental impact of buildings. Recent studies have highlighted the importance of both the operational and embodied energy attributable to buildings over their lifetime. The method of assessing lifetime building energy is known as life-cycle energy analysis. With Kyoto target obligations necessitating the quantification of greenhouse gas emissions at the national level, it seems increasingly probable that analyses of this kind will increase in use. If conducted in primary energy terms, such analyses directly reflect greenhouse gas emissions, except for a few processes which involve significant non-energy related emissions such as cement manufacture. A Life-Cycle Assessment would include these issues, as well as other environmental parameters, though probably with a corresponding decrease in system boundary completeness. This paper briefly explains some of the theoretical issues associated with life-cycle energy analysis and then uses an Australian based case study to demonstrate its use in evaluating alternative design strategies for an energy efficient residential building. For example, it was found that the addition of higher levels of insulation in Australia paid back its initial embodied energy in life-cycle energy terms in around 12 years. However, the saving represented less than $6 \%$ of the total embodied energy and operational energy of the building over a 100-year life cycle. This indicates that there may be other strategies worth pursuing before additional insulation. Energy efficiency and other environmental strategies should be prioritized on a life-cycle basis.

La consommation d'énergie est un paramètre très utilisé lorsque l'on veut mesurer l'impact des bâtiments sur l'environnement. Des études conduites récemment ont mis en lumière l'importance de l'énergie opérationnelle et celle de l'énergie intrinsèque dégagées par les bâtiments pendant leur durée de vie. L'analyse énergétique des bâtiments pendant leur cycle de vie est une méthode d'évaluation de l'énergie d'un bâtiment pendant sa durée de vie. Pour respecter les objectifs de la Conférence de Kyoto, il faut quantifier les émissions de gaz de serre au niveau national; il semble donc de plus en plus probable que la pratique de ces analyses va aller en augmentant. Si elles portent sur l'énergie primaire, ces analyses rendront parfaitement compte des émissions de gaz à effets de serre, sauf pour quelques procédés industriels, comme la fabrication du ciment, où les émissions de ces gaz ne sont pas liées à l'énergie. Toute évaluation du cycle de vie doit tenir compte de ces questions mais aussi d'autres paramètres environnementaux, mais avec, sans doute, une moindre netteté des limites des systèmes. Le présente communication expose brièvement quelques uns des problèmes théoriques liés aux analyses énergétiques sur le cycle de vie et s'appuie sur une étude de cas australienne pour démontrer son utilité à évaluer d'autres stratégies de conception de bâtiments à usage d'habitation à faible consommation d'énergie. On a constaté, par exemple, qu'en Australie le fait d'ajouter des niveaux d'isolation remboursait en 12 ans environ l'énergie intrinsèque initiale en terme d'énergie sur le cycle de vie. Toutefois, les économies représentaient moins de $6 \%$ de l'énergie intrinsèque totale et de l'énergie opérationnelle du bâtiment sur un cycle de vie de 100 ans. Cela veut dire qu'il serait peut être intéressant d'envisager d'autres stratégies avant d'augmenter l'isolation. On devrait donner priorité à l'efficacité énergétique et à d'autres stratégies environnementales sur la base du cycle de vie.

Keywords: life-cycle, energy analysis, residential buildings, embodied energy, Australia

\section{Introduction}

It is now well understood that buildings, in their operation, contribute to environmental degrada- tion, particularly where fossil fuels are used as the primary source of energy (England and Casler, 1995). Carbon dioxide emissions from coal-fired power plants, for example, contribute to global 
warming while other emissions (including sulphur dioxide and nitrous oxide) degrade water, air and soil. Consequently, reducing the fossil fuel based energy used to provide thermal comfort (heating, ventilation and cooling), lighting, hot water and other services (appliances and equipment) has been the focus of much research and development activity. The significance of greenhouse gases attributable to building operation is well understood (Pears, 1997). However, the environment is also degraded in the mining of raw materials, the manufacturing of building materials and products, and finally their transportation and assembly into buildings (Lawson et al., 1995). Over their lifetimes, buildings are maintained, refurbished, extended and finally demolished. During all these phases resources, such as fossil fuels, are consumed.

The assessment of the environmental impacts of buildings or other products throughout their lifetimes is known as Life-Cycle Assessment. LifeCycle Assessment (LCA) attempts to provide a measure of the overall environmental impact of a product (Häkkinen, 1994). Variables assessed include fossil fuel based energy and other nonrenewable resource requirements, as well as various emissions to soil, water and air. Qualitative judgements are often made in order that a single indicator may be developed, allowing direct comparison between products. Critics of this method (Lave et al., 1995) claim that the detailed focus of LCAs requires many potentially important processes to be neglected.

Life-Cycle Energy Analysis (LCEA) is an easily conducted form of Life-Cycle Assessment (LCA) and one which is particularly relevant to the building industry due to energy efficiency efforts over the last few decades. LCA forms part of the ISO 14000 series of standards on environmental management and is covered by the ISO 14040 group of standards.

Life-Cycle Energy Analysis (LCEA), however, uses energy as the only measure of environmental impact. Consequently, more detailed analyses of the energy attributable to buildings are possible. However, the purpose of LCEA is not to replace a broader environmental assessment method, such as LCA, but rather to facilitate decision-making concerning energy efficiency. Comparing the embodied energy of a building to its operational energy, for example, can indicate potential life cycle energy efficiency and conservation strategies. Similarly, LCEA concepts can be used to demonstrate the life cycle benefits of strategies designed to optimize the operational energy or embodied energy of a building. For example, thermal insulation has an embodied energy cost - the energy to make the insulation - but savings in operational energy accrue over time. LCEA can be used to estimate the net savings over the building's life, and perhaps more importantly, the 'energy payback period' $^{\prime}$ - the time taken for the initial embodied energy cost to be paid back by the ongoing operational energy savings accrued, or indeed, the $\mathrm{CO}_{2}$ payback period.

In summary, a building's life-cycle energy consists of its initial embodied energy, its recurrent embodied energy and its operational energy over its lifetime. There are powerful environmental reasons to use LCEA as a decision-making tool at the design development stage. The application of LCEA can result in substantial net reductions in energy use over the projected life of the building.

The aim of this paper is to demonstrate and discuss the use of LCEA in the context of energy efficient residential buildings.

\section{Background}

In life-cycle energy analysis (LCEA), the energy embodied in a building and the energy used in the operation of the building are calculated for the anticipated lifetime of the building: Simulation methods for embodied and operational energy have been developed but, like all methods, such simulations have in-built assumptions and limitations which reduce the accuracy of the results. These methods used to calculate embodied energy, operational energy and life-cycle energy, together with their limitations, are discussed below, and then a method for LCEA is demonstrated.

\section{Embodied energy}

The energy embodied in a product comprises the energy to extract, transport and refine the raw materials and then to manufacture components and assemble the product. The energy consumed directly at each phase is clearly definable and measurable. However, the energy required indirectly to support the main processes is less obvious 
and more difficult to measure. This includes the energy embodied in other inputs of goods and services and the machinery used to support these processes (for example, the forklift trucks that load materials in a factory). The total embodied energy comprises the direct energy purchased to support the process under consideration plus the indirect energy embodied in inputs to the process.

In the initial construction of buildings, the direct energy is the energy purchased by contractors onsite and off-site to facilitate any construction, prefabrication, administration and transport activities under their control (including sub-contractors). The indirect energy of construction comprises mainly the energy embodied in building materials. Together, these amounts of energy constitute the initial embodied energy of the building. However, during a building's life, embodied energy is added through goods and services used in maintenance and refurbishment. These are typically modelled by assuming typical replacement rates for items in the building (for example, paint) and is known as the recurrent embodied energy.

A number of methods have been developed to calculate embodied energy as completely and as accurately as possible: process analysis; inputoutput analysis; and hybrid analysis.

In theory, though not necessarily in practice, the simplest embodied energy analysis method is known as process analysis. This method focuses on the energy required for particular industrial processes. In brick-making, for example, the energy metered at the factory boundary can be measured (i.e. the direct energy requirement). However, such a measurement is incomplete because it excludes, for example, the energy used to extract clay from the ground and then to transport it to the brickworks (i.e. the indirect energy). Process analysis can be used to measure the energy used, per brick say, for many of these processes. However, at each stage there may be many large or small inputs of goods and services which cannot all be covered in detail using the process analysis method (Boustead and Hancock, 1979).

A method that can provide an estimate of all energy embodied in a product is known as inputoutput analysis. This method makes use of national statistical information compiled by governments for the purpose of analysing national economic flows between sectors. These economic flows can be translated into energy flows using average energy tariffs. While theoretically complete, this method has several methodological problems, discussed elsewhere (Treloar, 1997). Consequently, this method is not considered reliable for embodied energy analysis of an individual product.

A third method, known as hybrid analysis, combines the strengths of process analysis (reliable energy consumption figures for particular processes) with those of input-output analysis (theoretically complete system framework) while eliminating, as much as possible, their inherent weaknesses (incompleteness and errors respectively). The most important deficiency with the hybrid analysis method is the lack of a comprehensive and reliable database of energy use data from industry (Bullard et al., 1978). More often than not, the unreliable input-output data have to be relied upon for many processes which may include the main process or processes and which may be one or more transactions upstream from the main process.

\section{Primary versus secondary energy}

Since energy is the basic unit of measurement in an LCEA, the form of energy must be clarified. Energy is metered at the point of entry to the property or building. The energy used by the consumer is known as delivered energy. However, a considerable amount of energy is used to produce the delivered energy and it varies according to fuel type (for example, electricity or gas) and the means of producing the energy (for example, coal-fired power station or hydropower). Consequently energy should be measured in terms of primary energy - the energy required from nature (for example, coal) embodied in the energy consumed by the purchaser (for example, electricity). For every unit of electricity used in Australia, on average, approximately 3.4 units of primary energy such as coal are required (discussed in Treloar, 1997). This ratio of 3.4 to 1 for electricity production, or simply 3.4 , is termed the primary energy factor for electricity. Primary energy factors are proportional to energy related $\mathrm{CO}_{2}$ emissions. Therefore primary energy is a more appropriate measure of the environmental implications of energy use than delivered energy.

Primary energy factors should be applied to both the operational energy and embodied energy quantities, so that valid comparisons can be made. For example, electric hot water and gas-fired hot 
water systems are not comparable in delivered energy terms, especially if coal is required to make the electricity (assuming otherwise equal performance). Similarly, if competing building materials or systems are manufactured using different fuel sources, then a comparison in delivered energy terms is likely to be invalid.

\section{Operational energy}

Operational energy comprises the energy used for space heating and cooling, hot water heating, lighting, refrigeration, cooking and appliance and equipment operation. Space heating and cooling energy is often simulated using computer programs such as CHENATH, TRANSYS, TEMPAL and DOE2. Many of these programs are difficult to use, due to their complexity. For further information refer to Luther (1998).

Australian programs, such as VicHERS, designed for Victoria, a State of Australia, use the results of large numbers of results derived using a thermal simulation program to generate equations which are used in a more user-friendly 'front-end'. VicHERS allows numerous variations to a building to be modelled rapidly, though they may be subject to errors when modelling unusual conditions. Programs such as the Australian NatHERS (incidentally, designed for Australia), on the other hand, interface directly to the simulation engine and are therefore more reliable for modelling nonstandard conditions, such as highly efficient buildings. The CHENATH simulation engine within NatHERS (used for the case study in this paper) has a history of development, validation and modification. Its output remains, nevertheless, a simulation of the thermal performance of the building since it is subject to numerous limitations, errors and potentially faulty assumptions. Furthermore, simulation programs are incapable of modelling complex human behaviour. Despite the limitations, computer simulations allow large numbers of variables to be modelled and their impact evaluated for buildings not yet constructed.

\section{Life-cycle energy analysis}

The main benefit of LCEA is that the embodied energy costs of products, design modifications and strategies used to optimize operational energy can be evaluated. Life-cycle energy comprises the operational energy of the building and its initial and recurrent embodied energy - over its expected lifetime. Each has been described above. Life-cycle energy was calculated using the equation:

$\mathrm{LCE}=\mathrm{EE}_{\mathrm{i}}+\left(\mathrm{EE}_{\text {rec }}+\mathrm{OE}\right) \times$ building lifetime

where:

$\mathrm{LCE}=$ the life-cycle energy;

$\mathrm{EE}_{\mathrm{i}}=$ the initial embodied energy of building;

$\mathrm{EE}_{\mathrm{rec}}=$ the annual recurrent embodied energy (for example, in maintenance); and

$\mathrm{OE}=$ the annual operational energy (including space conditioning and other domestic energy uses).

Since the life-cycle period used in this analysis varied, demolition energy was not included. In any case, the energy required to demolish the building is generally considered to be very small compared to the rest of the life-cycle energy (Bekker, 1982). Furthermore, embodied energy savings from recycling or reusing demolished materials should be attributed to the next user, not to the demolished building (Tucker et al., 1993).

The life-cycle energy implications of an energy saving strategy need to be considered in net terms. For example, the installation of additional insulation would have an embodied energy cost at the start of the life of the building. Assuming no replacements are required over time (i.e. that the insulation lasts well), the annual benefits in thermal performance that accrue can be modelled as savings in energy consumption of the heating and cooling system. In reality, some of the benefits may be taken as improvements in comfort, for example, if there is no cooling system installed.

\section{Case study}

For simplicity and clarity, Life-Cycle Energy Analysis is demonstrated here for a residential project. The building analysed is the 'Green Home', a twostorey detached brick veneer house designed by Taylor Oppenheim Architects and built by Hotondo Builders in Melbourne, Australia.

The dwelling is located in Melbourne, Australia. Though it has a temperate climate, Melbourne has highly variable weather conditions. It has 41345 heating degree hours and 1343 cooling degree 
hours (Szokolay, 1982). Space heating, therefore, is the dominant energy use. Approximately half of all dwelling operational energy use in Victoria is for space heating (Energy Victoria, 1994, see Appendix for climate details).

This project is the result of a 'design and construct' competition held in 1992 by the Victorian Department of Planning and Development, in conjunction with the Australian Conservation Foundation (see Fig. 1). The house was designed with a number of energy-saving features such as double glazing. However, in this study the building was modelled with conventional single glazing for the purpose of evaluating additional insulation as an energy efficiency feature in isolation. Consequently, the heating and energy simulation results can be expected to be greater than those of the house as built.

\section{Embodied energy analysis method}

A hybrid embodied energy analysis method was used (see Background), with product quantities calculated using process analysis (i.e. analysing the building materials required for the initial construction of the building) and material energy intensities calculated using input-output analysis. The material energy intensities were then multiplied by the product quantities, and summed (see Table 1). Input-output analysis was also used to derive a figure for the direct energy of construction (Treloar, 1997, $0.876 \mathrm{GJ} / \mathrm{m}^{2}$ ). This ratio was factored into the calculations for the case study building (Table 1). The recurrent embodied energy was simulated using replacement factors for many of the items in the building. They included - among others - paint (10 years), windows (50 years), plumbing and electrical systems (25 to 75 years), appliances (13 to 25 years) and roofing materials ( 25 to 50 years). Building lifetime was assumed to be 100 years. Since there is an interrelationship between recurrent embodied energy and building lifetime, the results can be expected to differ as the durability of materials and the maintenance regimes adopted are varied.

The analysis included all major appliances that may be fitted to a building prior to hand-over (e.g. stove, microwave oven, dishwasher, heater,

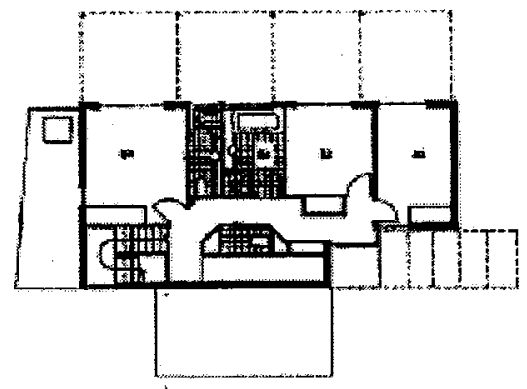

Figure 1b. First floor
Figure 1a. Ground floor

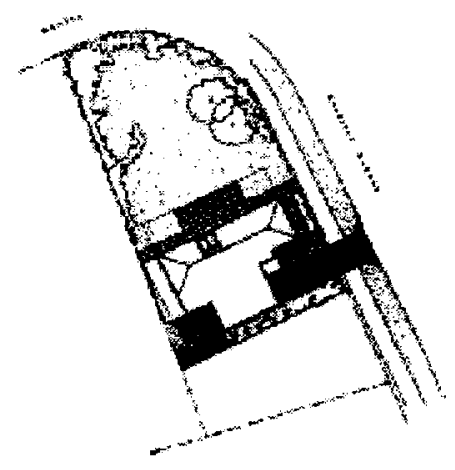

Figure 1c. Site plan

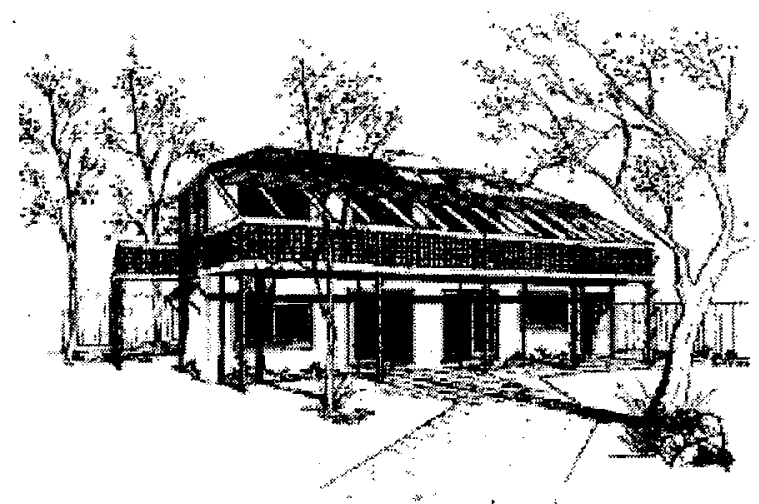

Figure 1d. Perspective drawing

Fig. 1. Case study building - 'Green Home' by Taylor Oppenheim architects and Hotondo builders, Melbourne (drawings: D. Oppenheim). 
Table 1. Embodied energy calculation for house

\begin{tabular}{llccc}
\hline Material & Unit & Quantity & $\begin{array}{c}\text { Energy Intensity } \\
(\mathrm{GJ} / \text { unit) }\end{array}$ & $\begin{array}{c}\text { Embodied } \\
\text { Energy (GJ) }\end{array}$ \\
\hline Brick & $\mathrm{m}^{2}$ & 288 & 0.884 & 255 \\
Timber & $\mathrm{m}^{3}$ & 21.5 & 11.7 & 251 \\
Concrete 30 MPa & $\mathrm{m}^{3}$ & 22.3 & 5.85 & 130 \\
Steel & $\mathrm{t}$ & 1.87 & 68.6 & 128 \\
Direct energy & - & - & - & 112 \\
Cement roof tiles & $\mathrm{m}^{2}$ & 126 & 0.751 & 95 \\
Reflective foil & $\mathrm{m}^{2}$ & 332 & 0.267 & 89 \\
Household appliances & $\$$ & 9480 & 0.008 & 73 \\
Copper & $\mathrm{t}$ & 0.11 & 607 & 66 \\
Furniture & $\$$ & 8000 & 0.008 & 64 \\
Carpet & $\mathrm{m}^{2}$ & 74.6 & 0.817 & 61 \\
Plasterboard 10 $\mathrm{mm}$ & $\mathrm{m}^{2}$ & 403.6 & 0.135 & 55 \\
Tile, ceramic & $\mathrm{m}^{2}$ & 35.7 & 1.47 & 52 \\
Screenings & $\mathrm{m}^{3}$ & 106 & 0.426 & 45 \\
Plastic & $\mathrm{t}$ & 0.14 & 308 & 44 \\
Fibreglass batts & $\mathrm{m}^{2}$ & 148 & 0.248 & 37 \\
MDF architrave $67 \mathrm{~mm}$ & $\mathrm{~m}$ & 366 & 0.098 & 36 \\
Plasterboard 13 mm & $\mathrm{m}^{2}$ & 153 & 0.168 & 26 \\
Concrete 20 MPa & $\mathrm{m}^{3}$ & 5.09 & 4.88 & 25 \\
MDF/particleboard & $\mathrm{m}^{3}$ & 2.70 & 8.52 & 23 \\
Concrete 15 MPa & $\mathrm{m}^{3}$ & 5.10 & 4.39 & 22 \\
Vitreous china & $\mathrm{kg}^{3}$ & 89.6 & 0.229 & 21 \\
OTHERS & - & - & - & 93 \\
TOTAL & - & - & - & 1803 \\
\hline
\end{tabular}

dish and clothes washing machines and clothes drier). Minor appliances, such as blenders and toasters, were not included. Furniture was included, but personal possessions, such as books, artworks, linen, cutlery, crockery and cooking implements, were excluded. A broader discussion of the life-cycle energy requirements associated with living (e.g. including belongings, cars, consumables, and vacations) is developed elsewhere (Treloar and Fay, 1998).

\section{Operational energy analysis method}

While some LCEA studies include only the heating and cooling energy, all household operational energy is included in this study (i.e. including 'non-thermal comfort' energy requirements such as the energy used for lighting, cooking, hot water, appliances and other power). The purpose of including non-thermal operational energy was to give a context to the relative importance of energy efficiency strategies such as adding more insulation. Heating and cooling energy requirements were simulated using the computer program NatHERS. Non-space conditioning energy requirements were derived by deducting typical figures for thermal energy requirements from figures for total operational energy requirements.

The U-values of the various elements of the building are listed below:

- Roof $=1.56 \mathrm{~W} / \mathrm{m}^{2} . \mathrm{K}$

- Ceiling $=0.44 \mathrm{~W} / \mathrm{m}^{2} . \mathrm{K}$

- Window $=4.99 \mathrm{~W} / \mathrm{m}^{2} \cdot \mathrm{K}$

- Wall $=0.65 \mathrm{~W} / \mathrm{m}^{2} \cdot \mathrm{K}$

- Floor $=0.68 \mathrm{~W} / \mathrm{m}^{2} . \mathrm{K}$

Roof and ceiling U-values are listed separately because the NatHERS program assumes the roof and ceiling belong to different zones.

The base case scenario for the house required a number of assumptions, some of which are default settings in the NatHERS program, such as air infiltration and ventilation rates, thermostat settings (heating to $21^{\circ}$ and cooling to $26^{\circ}$ ) and hours of operation (17 hours per day). Other assumptions and characteristics of the base case 
simulation, though not necessarily of the house as built, included:

- living areas have north orientation;

- construction comprises brick veneer external walls with stud framed internal walls, concrete slab to the ground floor, suspended timber first floor and tiled roof (see Fig. 2);

- walls have $50 \mathrm{~mm}$ of fibreglass insulation (i.e. a U-value of approximately $\left.1 \mathrm{~W} / \mathrm{m}^{2} . \mathrm{K}\right)$, ceilings have $100 \mathrm{~mm}$ of fibreglass insulation (i.e. a U-value of approximately $0.5 \mathrm{~W} / \mathrm{m}^{2} . \mathrm{K}$ ) and roof has foil insulation;

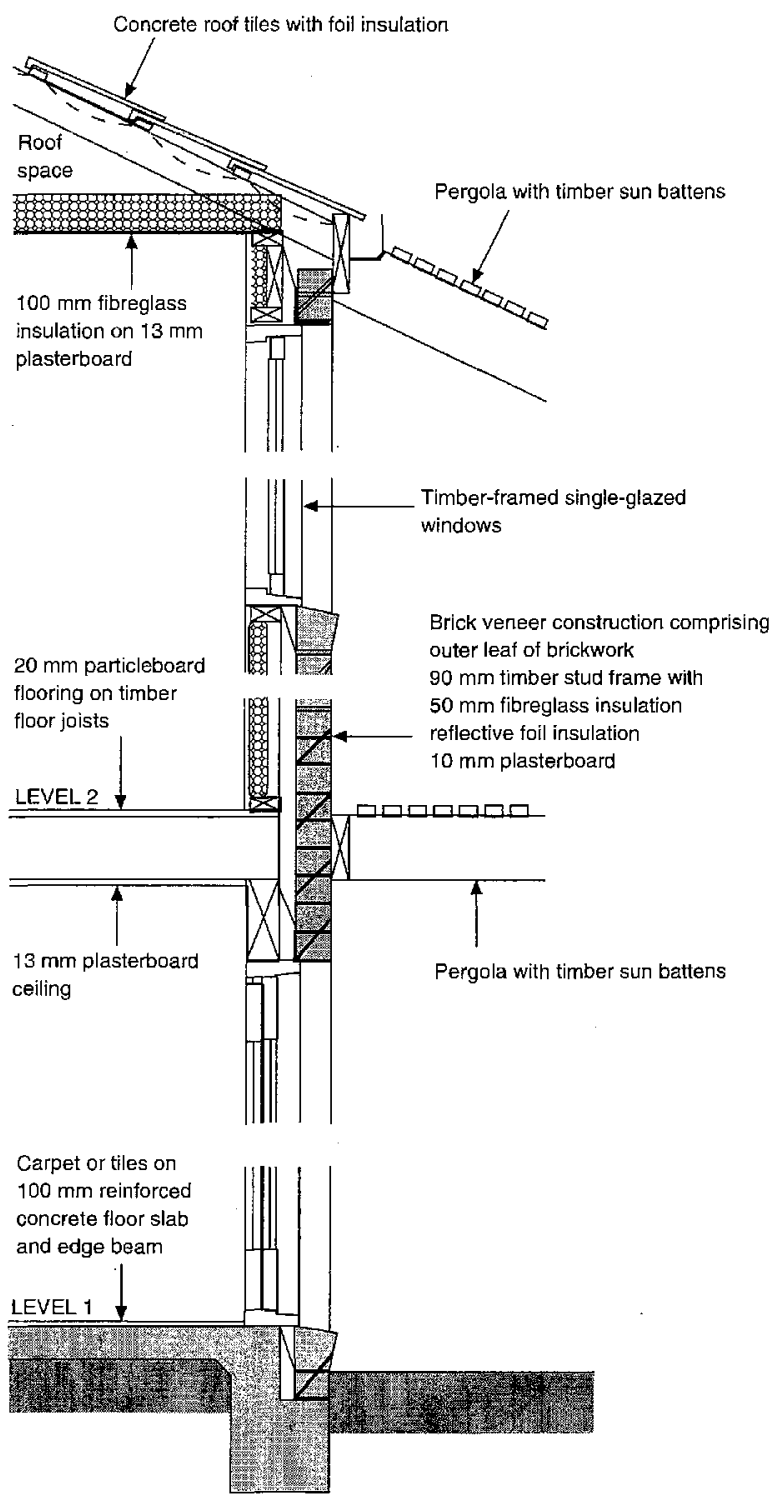

Fig. 2. Case study building - construction section (drawing: R. Fay).
- windows are single glazed and timber framed; and

- pergolas have timber shade battens protecting equatorial-facing windows (see Figs 1 and 2).

Heating was assumed to be delivered by a ducted gas-fired warm air system having an efficiency of $70 \%$ while the air conditioning system was assumed to have an efficiency of $290 \%$.

A single variation to the base case, a higher level of insulation, was then modelled. Insulation was increased from the base case to R2.5 bulk insulation in the walls, R1 bulk insulation and foil in the roof, and R4 bulk insulation in the ceiling.

\section{Life-cycle energy analysis method}

Annual operational energy consumption was assumed to remain constant throughout the life cycle of the house. However, future trends are difficult to predict due to a combination of efficiency improvements (reductions in energy use), increased user comfort expectations (increases in energy use) and changes in energy pricing, legislation, behaviour, personal affluence and community attitudes to the environment (net increases or reductions in energy use). Various models were produced using a range of lifetimes to demonstrate their implications for the case study building.

\section{Case study results}

The results for the embodied energy, operational energy and life-cycle energy are expressed as a square metre rate based on the habitable area of $128 \mathrm{~m}^{2}$, allowing comparison with other dwellings differing in size in this type of climate. The operational energy and embodied energy of the house were simulated for the Melbourne, Australia climate using a number of assumptions regarding construction and operational use patterns. For this reason, the results of this study may not accord with either the design predictions or the actual performance. Furthermore, they may not apply to other climates or building styles or types.

Only one energy efficiency measure, that of additional insulation, was analysed in life-cycle terms. However, this demonstration shows how other energy efficiency and conservation strategies can be considered in life-cycle terms both in terms of 
the net benefits and the proportional improvement to the total life-cycle energy.

\section{Embodied energy results}

Embodied energy was calculated for the base case and then for a higher level of insulation (Table 2). Initial embodied energy for the house was calculated to be $1803 \mathrm{GJ}\left(14.1 \mathrm{GJ} / \mathrm{m}^{2}\right.$ of floor area). This value is considerably higher than many other embodied energy studies for houses (for example, see Pullen, 1995), where values around $5 \mathrm{GJ} / \mathrm{m}^{2}$ were reported). This is because the results reported here were derived in primary energy terms, with a wider system boundary than most previous studies, including such features as appliances, landscaping and other small items often neglected.

Due to recurrent embodied energy requirements, the total embodied energy for the house increased over time (Table 2). For example, for the base case, the effects of replacing items in the building in the first 25 years amounted to $2.6 \mathrm{GJ} / \mathrm{m}^{2}$ of floor area. Included in the figures in Table 2 is the increasing life-cycle embodied energy for the building due to the addition of a higher level of insulation. The additional insulation increased the embodied energy of the house initially from the base case by $1.1 \mathrm{GJ} / \mathrm{m}^{2}$ of floor area (i.e. this was not a recurring item). At this stage, the operational energy of the house is not included.

\section{Operational energy results}

The thermal energy result for the base case, in primary energy terms was calculated to be $38.2 \mathrm{GJ} /$ annum (i.e., $0.30 \mathrm{GJ} / \mathrm{m}^{2}$.a). This house is relatively energy efficient, compared to an estimated average of approximately $53.6 \mathrm{GJ}$ (i.e. $0.42 \mathrm{GJ} / \mathrm{m}^{2}$.a) - based on an assumed $40 \mathrm{GJ}$ of

Table 2. Life-cycle embodied energy for the house

\begin{tabular}{cll}
\hline $\begin{array}{l}\text { Age of house } \\
\text { (years) }\end{array}$ & $\begin{array}{l}\text { Base case } \\
\left(\mathrm{GJ} / \mathrm{m}^{2}\right)\end{array}$ & $\begin{array}{l}\text { With additional insulation } \\
\left(\mathrm{GJ} / \mathrm{m}^{2}\right)\end{array}$ \\
\hline 0 & 14.1 & 15.2 \\
25 & 16.7 & 17.8 \\
50 & 23.5 & 24.6 \\
75 & 30.0 & 31.1 \\
100 & 35.4 & 36.5 \\
\hline
\end{tabular}

NB Increase each period is due to maintenance of elements not related to building insulation, hence the equal difference in each case of $1.1 \mathrm{GJ} / \mathrm{m}^{2}$. delivered energy (Loder et al., 1993) and a weighted primary energy factor of 1.34 used to account for a $22 \%$ cooling load and typical equipment efficiencies. The thermal energy result for the variation to the base case with the added insulation was $0.21 \mathrm{GJ} / \mathrm{m}^{2}$.a, representing a $30 \%$ reduction over the base case. As noted, the 'Green Home', as modelled, is already a relatively efficient building in thermal terms. Thus this 30\% improvement in heating and cooling energy efficiency is likely to be less than the improvement in thermal energy that would accompany the installation of insulation in a conventional home.

Non-thermal energy requirements were based on estimates for household energy use. It was assumed that the average new home in Victoria consumes 80 GJ of delivered energy (Anon., 1993) and that non-thermal energy comprises $50 \%$ of total energy use (for typical, not energy efficient houses, Energy Victoria, 1994). This 40 GJ of nonthermal delivered energy represents approximately $96 \mathrm{GJ}$ of primary energy (i.e. $0.75 \mathrm{GJ} / \mathrm{m}^{2}$ ), assuming an average primary energy factor of 2.4 for an even mix of electrical and gas use.

\section{Life-cycle energy results}

Life-cycle energy analyses over lifetimes of 0,25 , 50,75 and 100 years were carried out for the base case and then with added insulation. Table 3 demonstrates that the total life-cycle energy reduced only marginally due to the addition of insulation to the base case. Over 25 years, the improvement was only $2.7 \%$, increasing to $5.6 \%$ over 100 years. However, other factors are contributing to this comparison, such as increases in embodied energy due to replaced items. It is important to know the context for the relatively small improvement, because this might suggest that other strategies may reap more benefits, perhaps with lower initial embodied energy and financial costs.

Table 3. Life-cycle energy for the house as constructed

\begin{tabular}{ccc}
\hline $\begin{array}{l}\text { Age of house } \\
\text { (years) }\end{array}$ & $\begin{array}{l}\text { Base case } \\
\left(\mathrm{GJ} / \mathrm{m}^{2}\right)\end{array}$ & $\begin{array}{l}\text { Plus added insulation } \\
\left(\mathrm{GJ} / \mathrm{m}^{2}\right)\end{array}$ \\
\hline 0 & 14.1 & 15.2 \\
25 & 43.0 & 44.1 \\
50 & 76.0 & 72.6 \\
75 & 108.8 & 103.1 \\
100 & 140.4 & 132.5 \\
\hline
\end{tabular}


To aid decision-making regarding the additional insulation, it is more helpful to perform a lifecycle energy 'cost/benefit' analysis (Fig. 3). In this chart, the initial embodied energy required for the additional insulation (i.e. $1.1 \mathrm{GJ} / \mathrm{m}^{2}$ ) is paid back by net savings in heating and cooling energy (i.e. $0.09 \mathrm{GJ} / \mathrm{m}^{2} /$ annum) in 12.2 years. In 25 years, the net benefit represents $105 \%$ of the initial embodied energy 'cost' of the additional insulation. However, over 100 years the likely physical life of the house, if well maintained, the net benefit represents $718 \%$ of the initial embodied energy 'cost' of the additional insulation.

\section{Discussion}

Even considering that the overall net life-cycle saving due to the additional insulation was less than $6 \%$ of the total calculated for the case study building, the life-cycle energy cost/benefit analysis suggests that if saving energy (and the associated environmental impacts) in the long term is a priority, then additional levels of insulation may well be justified. However, other issues come into play in this decision, including:

- the assumption that the insulation will last a long time at peak performance

- whether renewable energy generation devices will be fitted (i.e. changing the type of benefits of energy efficiency measures from energy savings to system size reductions)

- the additional financial cost of the insulation, and whether that is paid back over time

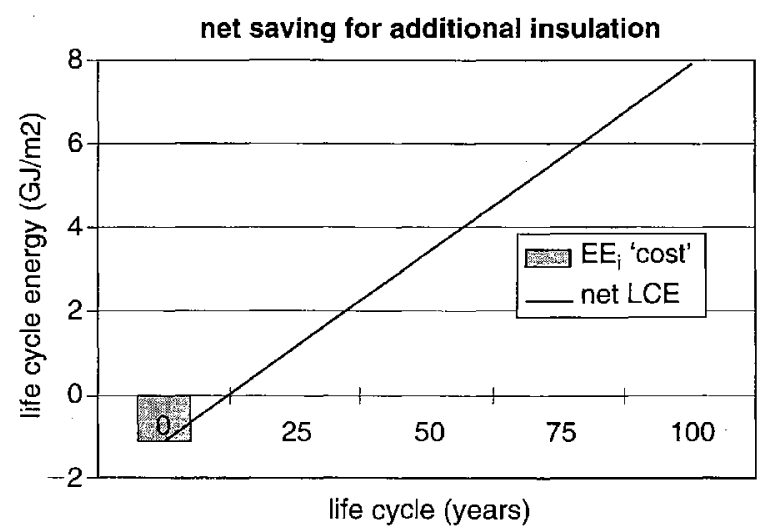

Fig. 3. Life-cycle energy (LCE) cost/benefit for additional insulation, comprising initial embodied energy 'cost' $\left(E E_{i}\right)$ and net life cycle energy saving (net LCE).
- other implications for construction and environmental impacts associated with using additional insulation

The broad life-cycle energy results given in Table 3 suggest that other energy efficiency and conservation strategies may be more effective than increased insulation, for example:

- high performance windows (for example, double glazing)

- high mass (for example, low embodied energy but massive materials)

- reduced infiltration losses (for example, an air-to-air heat exchanger in conjunction with tighter, less leaky, construction)

- wider thermostat settings and shorter heating times

- renewable energy generation facilities

- correctly sized windows oriented appropriately

\section{Conclusions}

In summary, while the additional insulation improved the life-cycle energy of the case study building by only a small amount, the decision was found to be worthwhile in net terms.

The LCEA method demonstrated here provides a framework for decision-making relating to energy efficiency strategies. It can provide information on:

- achieving a balance between embodied energy and operational energy over the anticipated lifetime of buildings (for example, how much insulation)

- the energy related environmental impacts of demolishing, replacing or refurbishing a building at various stages in its life

- other design strategies to reduce energy related environmental impacts

Other conclusions derived from LCEA research as described in this paper are:

- embodied energy is significant relative to operational energy

- as operational energy becomes lower (through efficiency improvements/lifestyle 
changes), embodied energy becomes even more significant

- while a net zero operational energy building is now achievable, a zero life-cycle energy building is likely to be more difficult

Energy is part of the broader sustainability problem, which also includes resource depletion, pollution from manufacturing and transportation, together with social and economic inequities. However, energy is currently an important parameter to optimize because of its national and global significance in gross terms. By widening the system boundary of the problem, counterintuitive opportunities for the development of energy conservation and environmental impact strategies can be identified.

Furthermore, in general environmental terms the relatively high importance of the initial embodied energy of a building in a temperate climate, as indicated here, may suggest that new construction is not always the best solution. Renovation of an existing building may offer considerable embodied energy and financial savings, with the opportunity to provide equal amenity and perhaps improved efficiency. For new buildings, design flaws such as redundant structure, inefficient planning and circulation, and ineffective shading devices and similar features present opportunities for developing optimization strategies. Other opportunities include substituting low energy intensity materials for high energy intensity materials, reducing construction waste, reusing products, using products with a high recycled content and designing for adaptability and deconstruction. Of course, further research is required to determine the potential benefits of such strategies in specific circumstances.

\section{Acknowledgments}

The authors wish to express their thanks to David Oppenheim of Taylor Oppenheim Architects and Michael Renwick of Hotondo Builders for allowing the 'Green Home' to be used as a case study. The authors would like to acknowledge the valuable comments made by the anonymous reviewers on an earlier version of this manuscript.

\section{References}

Anon. (1993) CSR Bradford Energy Conquest Design Awards. The Architecture Show (TAS), June/July, pp. 32-35.

Energy Victoria (1994) Energy Efficient Housing Manual: Design Guidelines and Case Studies, Renewable Energy Authority Victoria, East Melbourne.

Bekker, P.C.F. (1982) A life-cycle approach in building. Building and Environment, 17(1), 55-61.

Boustead, I. and G.F. Hancock (1979) Handbook of Industrial Energy Analysis, Ellis Horwood Limited, Chichester.

Bullard, C.W., Penner, P.S. and Pileti, D.A. (1978) Net energy analysis - handbook for combining process and I-O analysis. Resources and Energy, 1, 267-313.

England, R.W. and Casler, S.D. (1995) Fossil fuel use and sustainable development: evidence from U.S. inputoutput data, 1972-1985. Advances in the Economics of Energy and Resources, 9, 21-44.

Häkkinen, T. (1994) Environmental Impact of Building Materials, Technical Research Centre of Finland (VTT), Report No. 1590, Espoo, p. 38.

Lave, L.B., Cobas-Flores, E., Hendrickson, C.T. and McMichael, F.C. (1995) Using I-O analysis to estimate economy-wide discharges. Environmental Science and Technology, 29, 420-26.

Lawson, B., Partridge, H. and Gelder, J. (1995) Assessing the environmental impact of building materials. PRO 1. RAIA Environment Design Guide Redhill, Australia.

Loder and Bayly, R.J. Narrin \& Partners Pty Ltd, Sustainable Solutions Pty Ltd and PPK Consultants Pty Ltd (1993) Greenhouse Neighbourhood Project - A Technical Report, Department of Planning and Development, Melbourne.

Luther, M. (1998) An Introduction to Building Energy Performance Software. DES 21. The RAIA Environment Design Guide Redhill, Australia.

Pears, A. (1997) Greenhouse Gas Emissions and the Residential Sector. GEN 13. RAIA Environment Design Guide.

Pullen, S. (1995) Embodied Energy of Building Materials in Houses. Masters thesis, University of Adelaide, Adelaide, p. 227.

Szokolay, S.V. (1988) Climate Data and its Use in Design, RAIA Education Division, Canberra, p. 3.1.

Treloar, G. and Fay, R. (1998) Embodied Energy of Living. GEN 20. RAIA Environment Design Guide.

Treloar, G.J. (1997) Extracting embodied energy paths from input-output tables: towards an input-output based hybrid energy analysis method. Economic Systems Research, 9(4), 375-91.

Tucker, S.N., Salomonsson, G.D., et al. (1993) The Environmental Impact of Energy Embodied in Construction, (DBCE DOC 93/39M), CSIRO, Highett, p. 134. 


\section{Appendix: Climate information for Melbourne, Australia}

Latitude: $37^{\circ} 49^{\prime}$ S; Longitude: $144^{\circ} 58^{\prime} \mathrm{E}$; Altitude: $35 \mathrm{~m}$; Location: south-eastern coast

Mean daily sunshine hours: 5.7 average (3.4 June-8.1 Jan)

Mean daily cloud cover hours: 5.9 average (5.0 Feb-6.6 June)

Mean daily solar irradiation (Wh/ $\mathrm{m}^{2}$ ): 3973 average (6546 Jan-1620 Jun)

Relative humidity 0900: 68\% average (56 Jan-81 Jul)

Relative humidity 1500: $52 \%$ average (43 Jan-62 Jul)

Mean wind speed $(\mathrm{km} / \mathrm{h}): 12.3$

Maximum wind gust $(\mathrm{km} / \mathrm{h}): 119$

Mean temperature (DBT $\left.{ }^{\circ} \mathrm{C}\right): 15.2$ (9.9 Jul-20.7 Jan)

Mean maximum temperature (DBT ${ }^{\circ} \mathrm{C}$ ): 19.9 (13.5 Jul-26.5 Jan)

Mean minimum temperature (DBT $\left.{ }^{\circ} \mathrm{C}\right): 10.5$ (6.2 Jul-15.3 Feb)

Frost days: 10 (4 Jul, 2 Jun, 2 Aug, 1 May, $1 \mathrm{Sep}$ )

Heating degree hours: 41345 (1252 Feb-6082 Jul)

Cooling degree hours: 1343 (54 Dec, 828 Jan, 435 Feb, 26 Mar)

Solar excess degree hours: 8401 (2964 Dec, 3011 Jan, 2476 Feb)

Average diurnal temperature range $\left({ }^{\circ} \mathrm{K}\right): 9.4$

Average mean temperature range $\left({ }^{\circ} \mathrm{K}\right): 20.3$

Recommended design conditions: summer (DBT ${ }^{\circ} \mathrm{C}$ ): 34.5

Recommended design conditions: summer (WBT ${ }^{\circ} \mathrm{C}$ ): 21.0

Recommended design conditions: winter (DBT ${ }^{\circ} \mathrm{C}$ ): 4.5

Maximum rainfall intensity ( $\mathrm{mm}), 10$ minutes: 23

Maximum rainfall intensity (mm), 1 hour: 47

Thermal neutrality $\left(\mathrm{DBT}^{\circ} \mathrm{C}\right): 20.9-23.8$

Qualitative comments: A temperate climate, but due to its exposure to the anti-cyclone belt, it is highly variable even within the span of a few days. Summer temperatures often exceed $40^{\circ} \mathrm{C}$. In winter freezing is not uncommon. Precipitation is moderate and evenly distributed. Fog occurs some 20 days per year and the annual number of clear days is less than 50.

Two typical days: hourly temperatures $\left({ }^{\circ} \mathrm{C}\right)$; direct and diffuse horizontal radiation $\left(\mathrm{W} / \mathrm{m}^{2}\right)$

\begin{tabular}{|l|l|l|l|l|l|l|l|l|l|l|l|l|l|l|l|l|l|l|l|l|l|l|l|}
\hline 1 & 2 & 3 & 4 & 5 & 6 & 7 & 8 & 9 & 10 & 11 & 12 & 13 & 14 & 15 & 16 & 17 & 18 & 19 & 20 & 21 & 22 & 23 & 24 \\
\hline
\end{tabular}

Summer (Feb)

\begin{tabular}{|l|l|l|l|l|l|l|l|l|l|l|l|l|l|l|l|l|l|l|l|l|l|l|l|}
\hline 18.7 & 18.3 & 17.9 & 17.6 & 17.4 & 17.3 & 18.4 & 19.3 & 20.4 & 21.7 & 22.9 & 23.9 & 24.3 & 24.8 & 24.9 & 24.6 & 24.2 & 23.5 & 22.5 & 21.8 & 21.0 & 20.3 & 19.6 & 19.1 \\
\hline 0 & 0 & 0 & 0 & 0 & 2 & 59 & 153 & 252 & 340 & 403 & 459 & 479 & 448 & 393 & 321 & 217 & 112 & 26 & 1 & 0 & 0 & 0 & 0 \\
\hline 0 & 0 & 0 & 0 & 0 & 7 & 39 & 95 & 152 & 207 & 257 & 279 & 281 & 266 & 227 & 173 & 117 & 61 & 15 & 0 & 0 & 0 & 0 & 0 \\
\hline
\end{tabular}

Winter (July)

\begin{tabular}{|l|l|l|l|l|l|l|l|l|l|l|l|l|l|l|l|l|l|l|l|l|l|l|l|}
\hline 9.0 & 8.7 & 8.5 & 8.3 & 8.2 & 8.0 & 8.2 & 8.4 & 8.6 & 9.8 & 11.0 & 12.2 & 12.5 & 12.8 & 13.1 & 12.6 & 12.1 & 11.7 & 11.2 & 10.7 & 10.3 & 9.9 & 9.6 & 9.2 \\
\hline 0 & 0 & 0 & 0 & 0 & 0 & 0 & 4 & 38 & 75 & 114 & 129 & 123 & 112 & 81 & 51 & 18 & 1 & 0 & 0 & 0 & 0 & 0 & 0 \\
\hline 0 & 0 & 0 & 0 & 0 & 0 & 0 & 11 & 55 & 110 & 152 & 176 & 179 & 158 & 120 & 69 & 16 & 0 & 0 & 0 & 0 & 0 & 0 & 0 \\
\hline
\end{tabular}

Source: All information in this appendix from Szokolay, S.V. (1988) Climate data and its use in design, RAIA Education Division, Canberra, p. 3.1. 